Document downloaded from:

http://hdl.handle.net/10251/99650

This paper must be cited as:

Wang, Q.; Dunbing, T.; Yin, L.; Miguel A. Salido; Giret Boggino, AS.; Xu, Y. (2016). Biobjective optimization for low-carbon product family design. Robotics and ComputerIntegrated Manufacturing. 41:53-65. doi:10.1016/j.rcim.2016.02.001

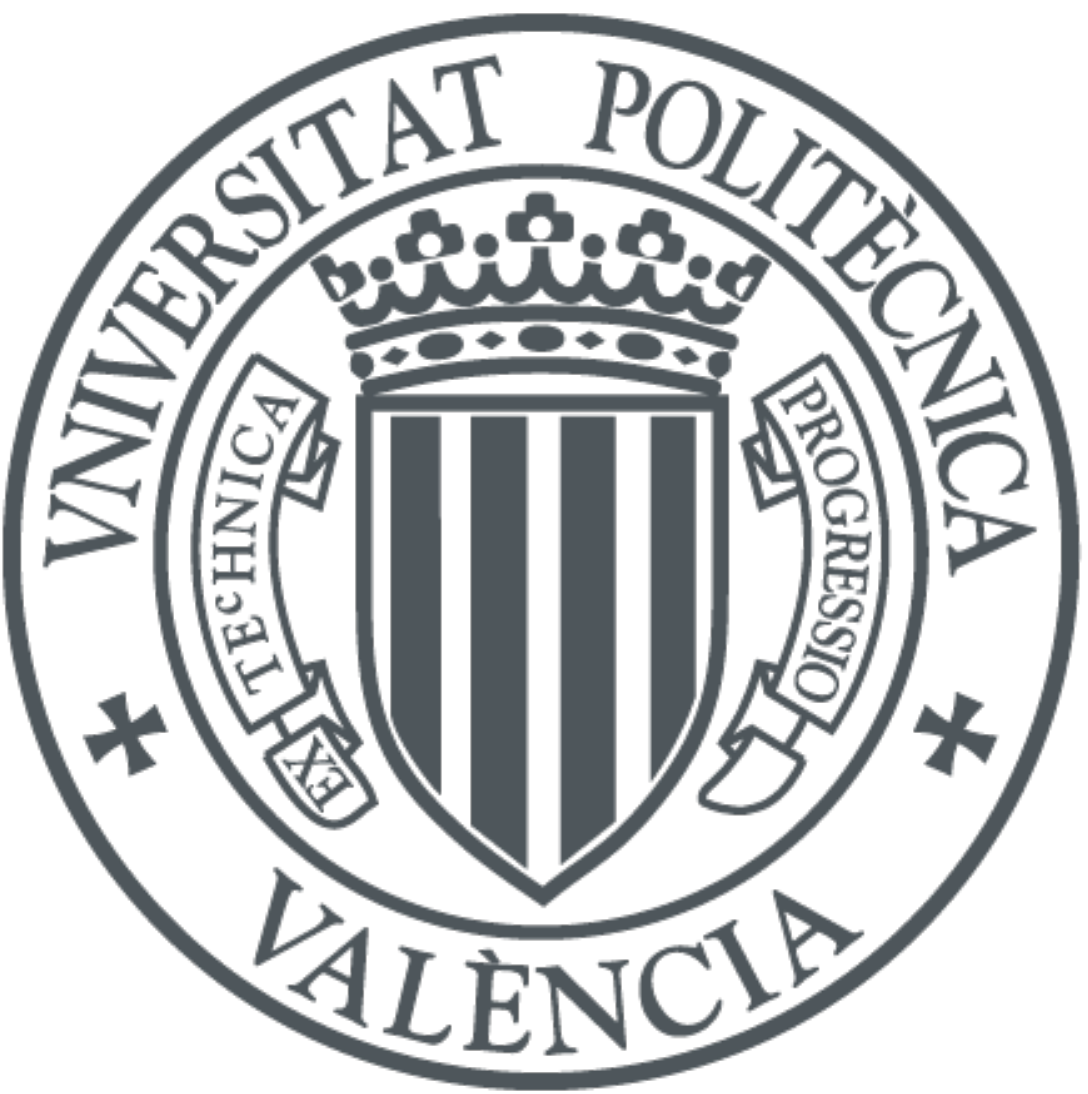

The final publication is available at

http://doi.org/10.1016/j.rcim.2016.02.001

Copyright Elsevier

Additional Information 


\title{
Bi-objective Optimization for Low-carbon Product Family Design
}

\author{
Qi Wang ${ }^{a}$, Dunbing Tang ${ }^{\mathrm{a}}$, LeiLei Yin ${ }^{\mathrm{a}}$, Miguel A. Salido ${ }^{\mathrm{b}}$, Adriana Giret ${ }^{\mathrm{b}}$ \\ ${ }^{a}$ College of Mechanical and Electrical Engineering, \\ Nanjing University of Aeronautics and Astronautics, Nanjing 210016, China \\ ${ }^{\mathrm{b}}$ Departamento de Sistemas Informáticos y Computación, \\ Universidad Politécnica de Valencia, Camino de Vera s/n 46071, Valencia, Spain
}

\begin{abstract}
Consumers, industry, and government entities are becoming increasingly concerned about the issue of global warming. With this in mind, manufacturers have begun to develop products with consideration of low-carbon. In recent years, many companies are utilizing product families to satisfy various customer needs with lower costs. However, little research has been conducted on the development of a product family that considers environmental factors. Therefore, low-carbon product family design that integrates environmental concerns is proposed in this paper. In low-carbon product family design, a new method of platform planning is investigated with consideration of cost and greenhouse gas (GHG) emission of a product family simultaneously. In this research, a low-carbon product family design problem is described at first, and then a GHG emission model of product family is established. Furthermore, to support low-carbon product family design, an optimization method is adopted to make a significant trade-off between cost and GHG emission to implement a feasible platform planning. Finally, the effectiveness of the proposed method is illustrated through a case study.
\end{abstract}

Keywords: low carbon design, carbon emissions, platform planning, product family design

\section{Introduction}

Climate change is one of the greatest challenges facing human society. The fourth

· Corresponding author, Tel: +86 25 84892051; Fax: +86 25 84891501. E-mail address: d.tang@nuaa.edu.cn 
assessment report of IPCC(2007) indicated that climate changes and global warming are attributed to greenhouse gas (GHG) emission result from human activities [1]. Products are viewed as one of the major sources of GHG emissions. Therefore, the enterprises have started to take steps to reduce GHG emission from their products and services under the mounting pressure stemming from the implementation of the Kyoto protocol and Copenhagen protocol [2]. These measures include product manufacturing with consideration of energy saving, green supply chain design, and so on. Cutting back on GHG emissions has become an inevitable trend. If an enterprise fails to promote relevant measures, it will soon find its products replaced by similar, but more environmental products.

"The product design and development phase influences more than $80 \%$ of the economic cost connected with a product, as well as $80 \%$ of the environmental and social impacts of a product, incurred throughout its whole life cycle" [3]. Hence, at the design stage, enterprises ought to considerate the GHG emission of a product. One of the most well-known research works is the work by Song et al. [4], who developed a low-carbon product design system based on BOM using the embedded GHG emissions data of the parts. The low-carbon product design system allows quick calculation of the GHG emission of a product, and a designer can easily and quickly evaluate alternative parts for the design of a low-carbon product. In further research, a collaborative framework has been established by Kuo [5] to help enterprises collect and calculate products' carbon footprints in a readily and timely manner throughout the entire supply chain.

In recent years, it is popular that products are designed and produced in the manner of a product family based on product platforms. The choice of platform not only affects the costs of a product family, but also influences the GHG emission of all product variants in the product family. For example, if a product platform with high carbon emission is shared in a product family, it will lead to higher GHG emission of some product variants. Recently, module sharing in a product family mainly pays attention to the cost-savings benefits. However, there are few researches focused on platform planning with consideration of environmental concerns, and current research 
on low-carbon product design is focused on a single product, not suitable to be employed to design a low-carbon product family. Therefore, in this research, the planning of product platform with simultaneous consideration of costs and GHG emissions is proposed, which is called low-carbon product family design.

The remainder of the paper is organized as follows. In section 2, we review relevant research about low-carbon product design and product family design. In section 3 , the problem of a low-carbon product family design is presented. In section 4 , the GHG emissions model of a product family is constructed, and the mathematical model of low-carbon product family design is illustrated. Section 5 gives an optimization method to support low-carbon product family design. In section 6 , a case study is included. The last section gives conclusions of the paper.

\section{Literature review}

\subsection{Low-carbon product design}

It is a fact that low-carbon products have become increasingly important. Recently, there has been growing interest in low-carbon product design. Jeong et al. [6] proposed an assessment method for eco-design improvement options using global warming and economic performance indicators. The external cost which converts the external effect of global warming into a monetary value and the life cycle cost of the product was chosen as the global warming and economic performance indicators, respectively. The global warming and economic performance indicators were combined to represent the total cost of the product. Wu et al. [7] proposed the policy design to stimulate the modular integrated application of low-carbon technologies. Bocken et al. [8] developed a novel eco-ideation tool to facilitate the generation of radical product and process that could lead to step-change in GHG emission reductions. Zhang et al. [9] proposed a way of calculating carbon footprints of products by focusing on the connection characteristics between components for low-carbon product structure design. The product was considered as the organic combination of connection units. By analyzing the parts' connection characteristics, 
the GHG emissions of connection units are calculated by recursive distribution approach of connection units' carbon footprint based on analytic hierarchy process method. The connection units with high GHG emissions are identified for low-carbon product design. To reduce the environmental impact and cost of the finished products, $\mathrm{Su}$ et al. [10] studied environmental impact in product's conceptual design phase and proposed a quantitative assessment of environmental impact and cost in the design phase. Kuo et al. [11] presented a method to decrease carbon footprints to an allowable value, while ensuring cost effectiveness, and also to make assessment of raw material suppliers. The environmental impact of the products and manufacturing cost are considered at the same time. In a word, more and more researches are focused on low-carbon product design in order to mitigate the impact of global warming on the environment.

\subsection{Product family design}

Today's product market has forced the companies to offer a large variety of products to match the diverse needs of customers while at the same time having to keep a low price. A successful way that many companies to offer this needed variety, meanwhile reducing the need for production cost is to launch product families based on a common platform. A product family is composed of sharing modules and variety modules. If the sharing modules design is reasonable, it can result in economies of scale from producing large volumes of the same modules, lower design costs from reduction of component types, and many other advantages arising from sharing modules.

Different criteria have been used for determining which components or modules to be shared in the family. Cost considerations have been the most common concern in regard to family design and platform development [12]. Fujita et al. [13] investigated product variety optimization under modular architecture with consideration of minimization of costs, and the cost saving from same design module instances that rise from the efficiency of production due to learning effects by reasonable module instances sharing in a product family. Martin et al. [14-16] developed three indexes- 
commonality index, CI, differentiation point index, DI, and setup cost index, SI-that provide surrogates for the indirect costs associated with product variety. A production cost model to support product family design optimization was developed by Park et al. [17]. This cost model based on a production cost framework is associated with the manufacturing activities. Johnson et al. [18] applied a process-based costing model to simultaneously assess the economic effects of material sharing and component sharing. Wang et al. [19] developed a method for constructing the product platform, under the objective of minimizing costs such as development cost and performance loss cost. This method is shown to be of higher computational efficiency for large product sets. Focusing on robust product family design, Hernandez et al. [20] presented a quantitative method for determining product platform extent for specific markets, considering conflicting demands including costs, performance and manufacturing considerations. Perera et al. [21] studied the effects of component or part standardization on life-cycle costs. They have explained how the component standardization reduces the costs of different phases of the product life cycle, and they also pointed out some of the possible disadvantages of component standardization. Expect for cost consideration, other criteria have been used in order to determine the components to be shared: Bill of Materials (BOM) (e.g. Steva et al. [22]), product attributes (e.g. Tucker and Kim 2008 [23]), product design variables (e.g. Khajavirad and Michalek 2008 [24], Khajavirad et al.2009 [25]), etc.

From the literature stated above, it is not difficult to find that strategy of sharing module between product variants in a family mainly emphasizes the cost. However, in product design, other factors should also be taken into account, such as the environmental performance of a product. Until now, little research work has been done on product platform planning with consideration of environment concerns, which still deserves extensive research. In this paper, a new method of platform planning is investigated with consideration of cost and GHG emission of a product family simultaneously. 


\section{Low-carbon product family design problem description}

With modularity, each product variant in a product family normally consists of a set of modules, some of which are unique module and some are replaceable module. The unique module is not shared by any other member of the family. The reason for not sharing may be something is essentially different between unique modules, or these module instances commonality may lead to obviously narrowing the difference among product variants. The other is replaceable module type. The notion of replaceable module type here is similar to that of 'variant module' proposed by [26]. For the replaceable module, customers do not care about these modules unless their performance level falls below a least value of customer needs. Therefore, the high-performance instance of a replaceable module may substitute the low-performance instance of the same module when configuring the product variants. A replaceable module is to provide a chance for the strategy of module sharing. For example, as shown in Fig. 1, each product variant has an initial module instance configuration based on the least value of customer needs. Suppose M1 is a replaceable module type, then module instance M1(3) can substitute M1(2) and M1(1) for design product variants $P^{(1)}$ and product variant $P^{(2)}$ respectively. In this situation M1(3) is regarded as a platform, and it is shared by all the product variants. Such the strategy of module sharing is widely used in industries for taking advantage of economies of scale. However, module sharing may lead to higher GHG emissions of the product family if it is not reasonably planned. For example, the performance level of an instance may be depending on its size, volume, and so on; and usually the larger size or volume of the instance, the higher performance level of the instance. In that case, if a low-performance instance is replaced by a high-performance instance, the higher GHG emissions of a product family cannot be avoided due to the performance level of the instance is related to the amount of raw materials. Furthermore, excess performance level of a module may lead to increasing power consumption in the usage phase also resulting in higher GHG emission of a product. Therefore, research on platform planning with consideration of GHG emission is essential for obtaining a 
low-carbon product family.

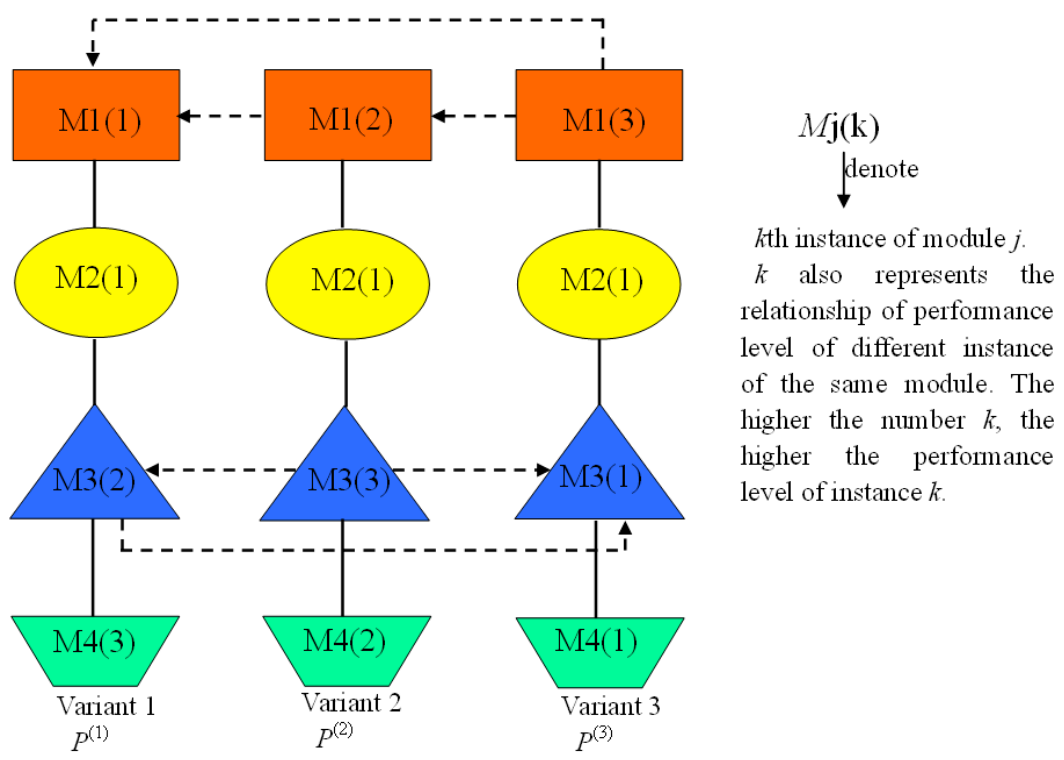

Fig. 1. The possibility of module sharing between product variants

As shown in Fig. 2, it is considered that there is a set of product variants in a product family according to market demand. Based on customers needs, each of product variants has an initial module instance configuration without any consideration of instance sharing. Each module may have more than one candidate instance, and different candidate instances provide different performance levels. This research is concerned with the following question: How to select instance of each module of each product variant with consideration of cost and GHG emission of the product family?

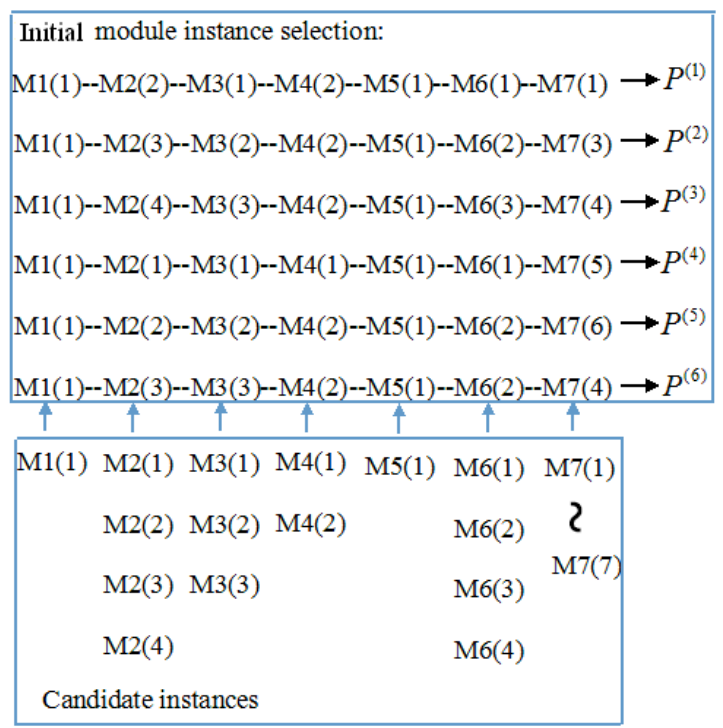

Fig. 2. An example of module instance configuration 


\section{Mathematical model of a low-carbon product family design}

\subsection{Decision variables for low-carbon product family design}

According to the low-carbon product family design problem description, the problem can be translated into the simultaneous determination of which of candidate instance is used for a module $j(1,2 \ldots ., J)$ of each product variant $P^{(\mathrm{i})}$, and it can be formulated by using binary variables, $x_{k}^{j(i)}$ which is defined as follows:

$$
x_{k}^{j(i)}= \begin{cases}1 & \text { if the } k \text { th instance of moduleis selected for product variant } i \\ & (i=1,2, \ldots \ldots I . j=1,2, \ldots \ldots, J ; k=1,2, \ldots \ldots, K) \\ 0 & \text { otherwise }\end{cases}
$$

Whether module instance $\mathrm{Mj}(k)$ is selected or not for product family design is determined by following equation.

$$
\gamma_{k}^{j}= \begin{cases}1 & \text { if } \sum_{i=1}^{I} x_{k}^{j(i)} \geqslant 1 \\ 0 & \text { otherwise }\end{cases}
$$

If $\gamma_{k}^{j}=1$, the module instance $\mathrm{Mj}(k)$ is selected for product family design, it means $\mathrm{Mj}(k)$ is eventually developed and produced, otherwise it is not developed and produced.

\subsection{Constraints of the model}

The problem of low-carbon product family design is described with three types of constraints, including performance level constraints, compatibility constraints and module instance combination constraints.

Performance level constraints. These are constraints arising from the fact that a high-performance module instance cannot be replaced by the module instance with low performance level when configuring the product variants. For example, suppose the initial instance configuration of module 2 of $P^{(1)}$ is M2(2), then M2(1) cannot be selected to design $P^{(1)}$ due to the limit of its performance level, while M2(3) can be selected. Performance level constraints can be expressed as follows: 


$$
P_{M j(k)}^{(i)} \geqslant P_{M j(\text { initial })}^{(i)}
$$

where, $P_{M j \text { (initial) }}^{(i)}$ is the performance level of initial instance configuration of module $j$ of $P^{(\mathrm{i})}$, it is the lowest performance level selection of module $j$ to design $P^{(\mathrm{i})} \cdot P_{M j(k)}^{(i)}$ is the performance level of $\mathrm{M} j(k)$ which is selected to design $P^{(\mathrm{i})}$.

Module instance compatibility constraints. These are constraints imposed on modules combination. They are mainly arising from the functional coupling between module instances. For instance, if a module instance $A$ has to be combined with module instance $B$ for realizing a function, then module instance $A$ is only compatible with $B$. If a design scheme of product variant includes module instances with incompatibility, it is an infeasible design scheme.

To model the compatibility constraints, module instance compatibility matrix $J$ is defined for representing the compatibility among module instances. The elements of matrix $J_{i j}$ are given by:

$$
J_{i j}= \begin{cases}1 & \text { if module instance is compatible with module instance } j \\ 0 & \text { otherwise }\end{cases}
$$

For the example of Fig. 1, suppose all module instances are compatible except for M1(2) is not compatible with M3(2). Then the compatibility matrix $J$ can be

\begin{tabular}{|c|c|c|c|c|c|c|c|c|c|c|}
\hline \multicolumn{11}{|c|}{$M 1(1) M 1(2) M 1(3) M 2(1) M 3(1) M 3(2) M 3(3) M 4(1) M 4(2) M 4($} \\
\hline$M 1(1)$ & 1 & 1 & 1 & 1 & 1 & 1 & 1 & 1 & 1 & 1 \\
\hline$M 1(2)$ & 1 & 1 & 1 & 1 & 1 & 0 & 1 & 1 & 1 & 1 \\
\hline$M 1(3)$ & 1 & 1 & 1 & 1 & 1 & 1 & 1 & 1 & 1 & 1 \\
\hline$M 2(1)$ & 1 & 1 & 1 & 1 & 1 & 1 & 1 & 1 & 1 & 1 \\
\hline$M 3(1)$ & 1 & 1 & 1 & 1 & 1 & 1 & 1 & 1 & 1 & 1 \\
\hline$M 3(2)$ & 1 & 0 & 1 & 1 & 1 & 1 & 1 & 1 & 1 & 1 \\
\hline$M 3(3)$ & 1 & 1 & 1 & 1 & 1 & 1 & 1 & 1 & 1 & 1 \\
\hline$M 4(1)$ & 1 & 1 & 1 & 1 & 1 & 1 & 1 & 1 & 1 & 1 \\
\hline$M 4(2)$ & 1 & 1 & 1 & 1 & 1 & 1 & 1 & 1 & 1 & 1 \\
\hline$M 4(3)$ & 1 & 1 & 1 & 1 & 1 & 1 & 1 & 1 & 1 & 1 \\
\hline
\end{tabular}
represented as follows:

Module instance combination constraints. It is a design constraint which restricts the mix of module instances to provide a feasible design scheme for product variant. Some module instances need to satisfy some design constraints based on a specific problem. For example, in an electronic product, if there is a module to provide power 
for several other modules, selection of such a module is affected by the selection of other related modules. Such constraints can be expressed as follows:

$$
\sum_{j=1}^{J} \sum_{k=1}^{K} P_{M j(k)} x_{k}^{j(i)} \alpha_{j} \geqslant \sum_{j=1}^{J} \sum_{k=1}^{K} P_{M j(k)} x_{k}^{j(i)} \beta_{j}(i=1,2 \ldots \ldots, I)
$$

where, $P_{M j(k)}$ is a performance level of $\mathrm{Mj}(k), \alpha_{j}$ and $\beta_{j}$ are binary variables. For example, in an electronic product, $P_{M j(k)}$ is demand or supply power capacity of $\mathrm{M} j(k)$, if module $j$ is power supply module, then $\alpha_{j}=1, \beta_{j}=0$, otherwise, $\alpha_{j}=0$, $\beta_{j}=1$.

\subsection{Objective for low-carbon product family design}

To design a low-carbon product family, the cost and GHG emissions of a product family are taken into account simultaneously. The objective function of cost $C$ and GHG emissions $G_{\mathrm{T}}$ of a product family are formulated as follows, respectively.

\section{Cost model}

In this paper, we adopt the cost model from [13], which was proposed for product variety optimization. The total cost consists of fixed and variable cost.

$$
C=C^{f}+C^{v}
$$

The fixed cost $C^{f}$ is to be calculated with the following equations.

$$
\begin{gathered}
C^{f}=C_{0}^{f}+\sum_{i=1}^{I} C_{p(i)}^{f}+\sum_{k=1}^{K} \sum_{j=1}^{J} C_{f k}^{M j} \gamma_{k}^{j} \\
C_{p(i)}^{f}=\alpha_{f}^{p} \sum_{k=1}^{K} \sum_{j=1}^{J} N_{k}^{j} x_{k}^{j(i)} \quad(i=1,2 \ldots \ldots, I) \\
C_{f k}^{M j}=\alpha_{f}^{M j} N_{k}^{j} \quad(j=1,2 \ldots \ldots . J ; k=1,2, \ldots \ldots K)
\end{gathered}
$$

where, $C_{0}^{f}$ is hidden fixed cost that does not relate to any kind numbers and unit number, $C_{p(i)}^{f}$ is fixed cost per product kind, $C_{f k}^{M j}$ is fixed cost per module kind, $N_{k}^{j}$ is the number of primitive elements of $k$ th instance of module $j$, and the 
primitive elements can be explained according to the product to be designed. It is assumed that the performance level of module is simply proportional to the number of the primitive elements such as in typical microchips, where the number of transistors is representative to their performance under the same mounting density [13]. $\alpha_{f}^{p}$ and $\alpha_{f}^{M j}$ are coefficients related to a product and a module respectively.

The variable cost $C^{v}$ consists of material cost $C_{m a}^{v}$, manufacturing cost of modules $C_{m u}^{v}$ and assembly cost of products $C_{a s}^{v}$. They are formulated as follows:

$$
\begin{gathered}
C^{v}=C_{m a}^{v}+C_{m u}^{v}+C_{a s}^{v} \\
C_{m a}^{v}=\sum_{k=1}^{K} \sum_{j=1}^{J}\left(\alpha_{v}^{m j} N_{k}^{j}+\beta_{v}^{m j}\right) U_{k}^{j} \\
U_{k}^{j}=\sum_{i=1}^{I} U^{(i)} x_{k}^{j(i)}(j=1,2 \ldots \ldots J ; k=1,2, \ldots \ldots K) \\
C_{m u}^{v}=\sum_{k=1}^{K} \sum_{j=1}^{J} \sum_{u=1}^{U_{k}^{j}}\left(\alpha_{v}^{f j} N_{k}^{j}\right) L^{f}(u) \\
C_{a s}^{v}=\sum_{u=1}^{U^{P}} c_{a}^{v} L^{a}(u)
\end{gathered}
$$

where, $\left(\alpha_{v}^{m j} N_{k}^{j}+\beta_{v}^{m j}\right)$ is a unit material cost per module, $U_{k}^{j}$ is product unit number of $\operatorname{Mj}(k), \alpha_{v}^{f j} N_{k}^{j}$ is the initial unit manufacturing cost per module $M j(k), \beta_{v}^{m j}$ is material cost for interfaces. $c_{a}^{v}$ is the initial unit assembly cost per product. $\alpha_{v}^{m j}, \beta_{v}^{m j}$ and $\alpha_{v}^{f j}$ is the coefficient that depend on module $j \cdot L^{f}(u)$ denotes the learning effect in module manufacturing, which is calculated with $L^{f}(u)=u^{\frac{\operatorname{In} r_{v}^{f}}{\ln 2}}$ under the learning ratio $r_{v}^{f} . L^{a}(u)=u^{\frac{I n r_{v}^{a}}{I n 2}}$ indicates the learning effect in product assembly. $U^{(i)}$ is the production unit number of product variant $P^{(i)} \cdot U^{P}$ is the total unit number of products, and it is calculated with $U^{P}=\sum_{i=1}^{I} U^{(i)}$.

\section{GHG emission model}


The GHG emissions model of a product family is established in this paper. The total GHG emissions of a product family are related to module instance configuration of each product variant, production volumes of each product variant, and so on. Total GHG emission of a product family is defined by summing GHG emissions of five phases, which can be formulated as follows:

$$
G_{T}=G_{t m}+G_{t p}+G_{t d}+G_{t u}+G_{t r}
$$

where,

$G_{\mathrm{T}}$ : the total amount of GHG emission of a product family;

$G_{\mathrm{tm}}$ : the amount of GHG emission from use of raw materials stage of a product family;

$G_{\mathrm{tp}}$ : the amount of GHG emission from manufacturing stage of a product family;

$G_{\mathrm{td}}$ : the amount of GHG emission from distribution stage of a product family;

$G_{\mathrm{tu}}$ : the amount of GHG emission from use stage of a product family;

$G_{\mathrm{tr}}$ : the amount of GHG emission from end of life stage of a product family.

Calculation of the GHG emissions in each stage follows the method described below.

$G_{\mathrm{tm}}$ : The GHG emission of this stage mainly stems from the refinement and transport of raw materials. In this paper, it is assumed that the different instance of the same module is made from the same raw materials for simplicity. $G_{\mathrm{tm}}$ is calculated by the following equations.

$$
\begin{gathered}
G_{t m}=\sum_{j=1}^{J} \sum_{k=1}^{K} U_{k}^{j} G_{k-\text { weight }}^{j} E_{j}^{M} \\
G_{k-\text { weight }}^{j}=m_{N} N_{k}^{j} \quad(j=1,2 \ldots \ldots J ; k=1,2, \ldots \ldots K)
\end{gathered}
$$

where, $E_{j}^{M}$ is the amount of GHG emissions per unit raw materials $j\left(\mathrm{kgCO} \mathrm{CO}_{2} e \mathrm{~kg}\right)$, and the module $j$ is made of the raw materials $j, G_{k-w e i g h t}^{j}$ is the amount of raw materials to manufacture $\mathrm{Mj}(\mathrm{k})(\mathrm{kg}), m_{\mathrm{N}}$ is the coefficient that depends on the amount of raw materials to manufacture $N_{k}^{j}$. 
$G_{\mathrm{tp}}$ : During the manufacturing stage, all modules are manufactured, and all product variants are assembled. Hence, it is considered here that $G_{\mathrm{tp}}$ consists of GHG emissions $G_{t m m v}^{f}$ of module manufacturing stage and GHG emissions $G_{t p a v}^{v}$ of product assembly stage. $G_{\text {tp }}$ is defined as follows:

$$
G_{t p}=G_{t m m v}^{f}+G_{t p a v}^{a}
$$

In this paper, the direct GHG emissions in the manufacturing process are omitted, and only the GHG emissions associated with energy consumption are considered. The amount of GHG emissions from manufacturing stage is difficult to assess. Because it is determined by many factors such as product attributes, process route, processing method, etc. Here, we consider the module manufacturing on production lines, and suppose the energy consumption per unit time of the equipment is fixed, then energy consumption of manufacturing module depends on the time of manufacturing module. Hence, energy consumption of manufacturing module stage is indirectly obtained by calculation of the time of manufacturing module. The total production time $T_{t m m v}^{f 1}$ of manufacturing module is calculated by summing unit production time across implemented modules over products as follows:

$$
T_{t m m v}^{f 1}=\sum_{k=1}^{K} \sum_{j=1}^{J} \sum_{u=1}^{U_{k}^{j}} t_{v k}^{f j} L^{f}(u)
$$

where, $t_{v k}^{f j}$ is the initial unit manufacturing time per module $M j(k)$, it is defined with the following equation.

$$
t_{v k}^{f j}=t_{v}^{f j} N_{k}^{j} \quad(j=1,2 \ldots \ldots J ; k=1,2, \ldots \ldots K)
$$

where, $t_{v}^{f j}$ is the coefficient that depend on module $j$.

The total GHG emissions from module manufacturing stage can be calculated with the following equation.

$$
G_{\text {tmm } v}^{f}=T_{t m m v}^{f 1}\left(\sum_{u=1}^{U} E_{a v / u} e_{u}^{M}\right)
$$

where, $E_{a v / u}$ is the amount of $u$ th energy consumption per unit production time in 
module manufacturing process, $e_{u}^{M}$ is the GHG emission factor of the $u$ th energy. $U$ is the kind number of energy consumption in module manufacturing process.

By the same way, we can obtain the amount of GHG emissions from product assemble stage. The assembly time of all product variants can be calculated using Eq.(23).

$$
T_{t p a v}^{a}=\sum_{u=1}^{U^{P}} t_{v}^{a} L^{a}(u)
$$

where, $t_{v}^{a}$ is the initial unit assembly time per product. $L^{a}(u)=u^{\frac{I n r_{v}^{a}}{\ln 2}}$ indicates the learning effect in product assembly.

The amount of GHG emissions of a product family from product assembly stage can be calculated as follows:

$$
G_{\text {tpav }}^{a}=T_{\text {tpav }}^{a}\left(\sum_{f=1}^{F} E_{a s / f} e_{f}^{A}\right)
$$

where, $E_{a s / f}$ is the $f$ th energy consumption per unit assembly time of a product, $e_{f}^{A}$ is the carbon emission factor of the $f$ th energy. $F$ is the kind number of energy consumption in product assembly process.

$G_{\mathrm{td}}$ : The GHG emissions of this stage stem from the fuel combustion of mobile sources. During the distribution stage, the GHG emissions are related to weight of transport, transport model, travel distance, etc. It is assumed that the weight of a module is equal to the amount of raw materials to manufacture the module, and the summing of weight of all modules is equal to the weight of the product. In this paper, suppose all product variants are transported to the same location, and the transport model is same. $G_{\mathrm{td}}$ is calculated as follows:

$$
\begin{gathered}
G_{\text {weight }}^{p(i)}=\sum_{k=1}^{K} \sum_{j=1}^{J} G_{k-\text { weight }}^{j} x_{k}^{j(i)}(\mathrm{i}=1,2, \ldots \ldots, I) \\
G_{t d}=\left(\sum_{i=1}^{n} G_{\text {weight }}^{p(i)} U^{(i)}\right) E^{D} S(\mathrm{i}=1,2, \ldots \ldots, I)
\end{gathered}
$$

The GHG emission for transport model is measured in (ton-km). $E^{D}$ is a 
coefficient, and it depends on the transport mode $\left(\mathrm{kgCO}_{2} e / \mathrm{tkm}\right) . S$ is the transport distance $(\mathrm{km})$.

$G_{\text {tu }}$ : In the use stage, the GHG emissions mainly stem from the energy consumption of a product. It is influenced by the time of operation in use and the lifetime of the product. In this paper, it is assumed that the power consumption of a product is approximately equal to the sum of power consumption of all constituent modules. Such assumption may be only employed for some product types, such as electronic product. It cannot be employed for all product types. In this paper, it is assumed that the electrical energy is used to support the working of a product, then $G_{\mathrm{tu}}$ is calculated as follows:

$$
\begin{gathered}
G_{t u}=\sum_{i=1}^{n} G_{u s}^{p(i)} U^{(i)}(\mathrm{i}=1,2, \ldots \ldots, I) \\
G_{u s}^{p(i)}=P_{\text {power }}^{(i)} \times T_{w} \times E F \quad(\mathrm{i}=1,2, \ldots \ldots, I) \\
P_{\text {power }}^{(i)}=\sum_{k=1}^{K} \sum_{j=1}^{J} P_{k-m}^{j} x_{k}^{j(i)} \quad(\mathrm{i}=1,2, \ldots \ldots, I)
\end{gathered}
$$

where, $G_{u s}^{p(i)}$ is the total amount of GHG emissions of $P^{(\mathrm{i})}$ from use stage, $P_{\text {power }}^{(i)}$ is the electric power of $P^{(\mathrm{i})}, T_{w}$ is the total operating time of a product in whole life cycle, $E F$ is the emission factor for electricity, $P_{k-m}^{j}$ is the electric power of module $\operatorname{Mj}(k)$.

$G_{t r}$ : During this stage, the recovery methods of the recyclable materials and disposal modes are remaining waste. The amount of GHG emissions depends on the type and weight of raw material of the module. $G_{t r}$ is calculated using the equation as follows:

$$
G_{T m}=\sum_{k=1}^{K} \sum_{j=1}^{J} U_{k}^{j} G_{k-w e i g h t}^{j} E_{j}^{\text {end }}
$$

where, $E_{j}^{\text {end }}$ is a coefficient, it depends on the amount of GHG emissions for disposal 
per unit raw materials $j$.

To summarize, the objective for a low-carbon product family design for the trade off between total cost $f_{1}$ and total GHG emissions $f_{2}$ is represented as follows:

$$
\left\{\begin{array}{l}
\min f_{1}=C \\
\min f_{2}=G_{T}
\end{array}\right.
$$

\section{An optimization method for low-carbon product family design}

As shown in Fig. 3, the proposed optimization method for low-carbon product family design is divided into three steps: (1) For product variant $P^{(\mathrm{i})}$, generate an initial design scheme set represented by matrix $M^{(\mathrm{i})}$; (2) After filtering some unfeasible design schemes from $M^{(\mathrm{i})}$ according to constraints, get a feasible design scheme set represented by matrix $Q^{(\mathrm{i})}$; (3) Based on $Q^{(\mathrm{i})}$, a low carbon product family planning scheme which is represented by matrix $D$ is generated by genetic algorithm(GA) optimization with simultaneous consideration of cost and GHG emission.

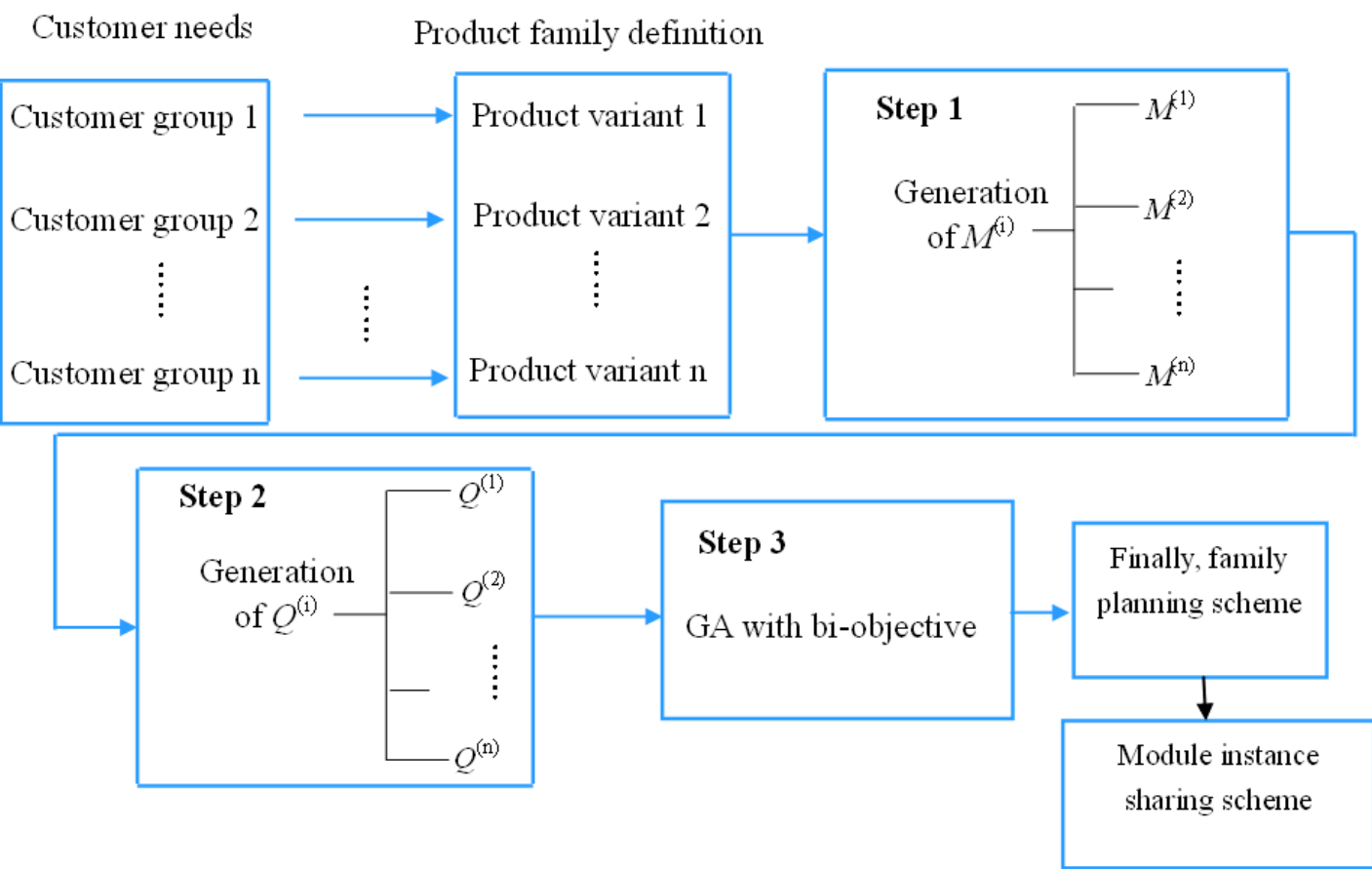

Fig. 3. Outline of the optimization method

Step 1: $M^{(\mathrm{i})}$ generation 
In this step, the initial design scheme set of each product variant $i$ will be generated based on their initial module instance configuration and feasible candidate module instances. Here, a feasible candidate module instance means that the performance level of the candidate module instance can meet the demand of customers. All the initial design schemes of a product variant can be obtained by an enumeration algorithm, and they are stored in a matrix $M$. For example, as shown in Fig. 2, according to the initial module instance configuration of $P^{(1)}$ and feasible candidate module instance, the initial design scheme set of $P^{(1)}$ was obtained as shown in Fig. 4. Each column of $M^{(1)}$ represents a initial design scheme of $P^{(1)}$. The element of the matrix, $M_{i, j}^{(1)}=k$ to represent the module instance $M i(k)$, is used within the $j$ th initial design scheme of $P^{(1)}$. For example, $M_{2,1}^{(1)}=2$ representing M2(2) is selected within the first initial design scheme of $P^{(1)} . P_{c n}^{i}$ indicates the $n$th initial design scheme of initial design scheme set of $P^{(\mathrm{i})}$. The $M^{(\mathrm{i})}$ of each product variant $i$ can be obtained in the same way.

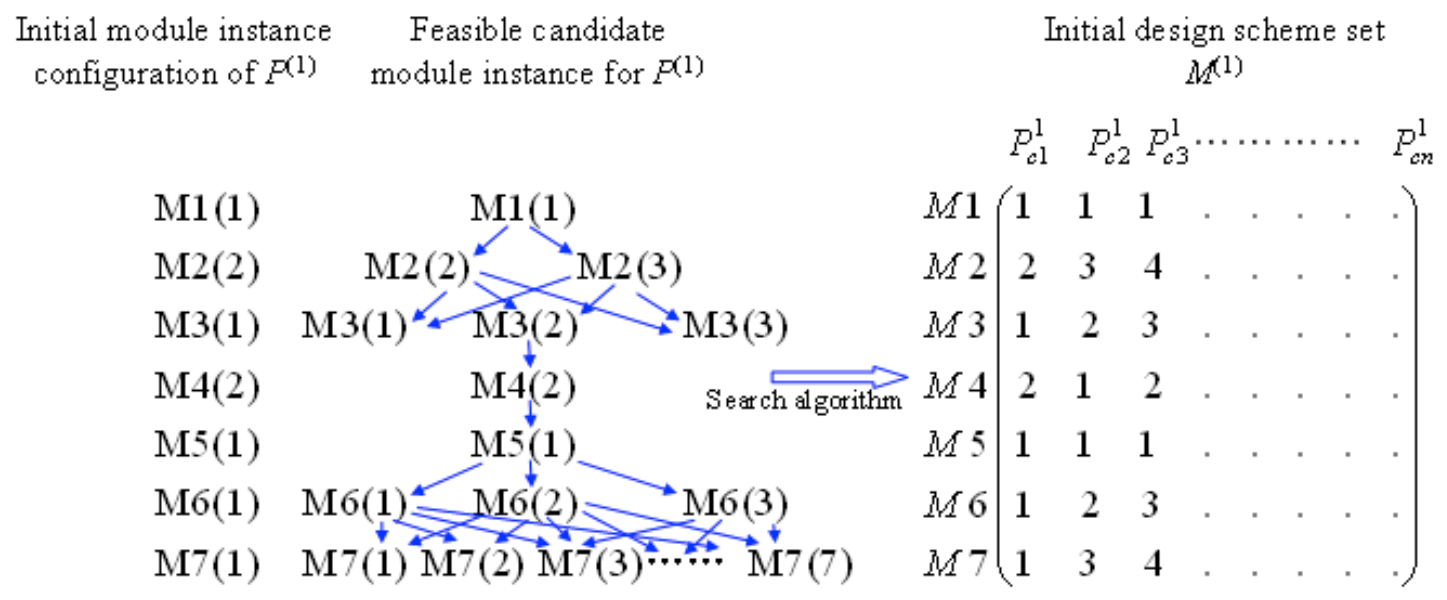

Fig. 4. An process of generation $M^{(1)}$

\section{Step 2: $Q^{(i)}$ generation}

Not all initial design schemes in $M^{(\mathrm{i})}$ are feasible for product variant $i$. Because some initial design schemes violate compatible constraints and module instance combination constrains. These infeasible design schemes shall be removed. In this 
step, the feasible design scheme set of $P^{(\mathrm{i})}$ will be obtained by removing infeasible design scheme in $M^{(i)}$, and the feasible design scheme set of $P^{(i)}$ is represented by matrix $Q^{(i)}$. As shown in Fig. 5, the infeasible design scheme is removed in $M^{(1)}$, only those feasible design schemes are remained. Finally, the feasible candidate design scheme set of $P^{(1)}$ are obtained, and they are stored in matrix $Q^{(1)}$. Each column of $Q^{(1)}$ represents a feasible design scheme for $P^{(1)}$. $P_{f m}^{i}$ indicates the $m$ th feasible design scheme of $P^{(\mathrm{i})}$.

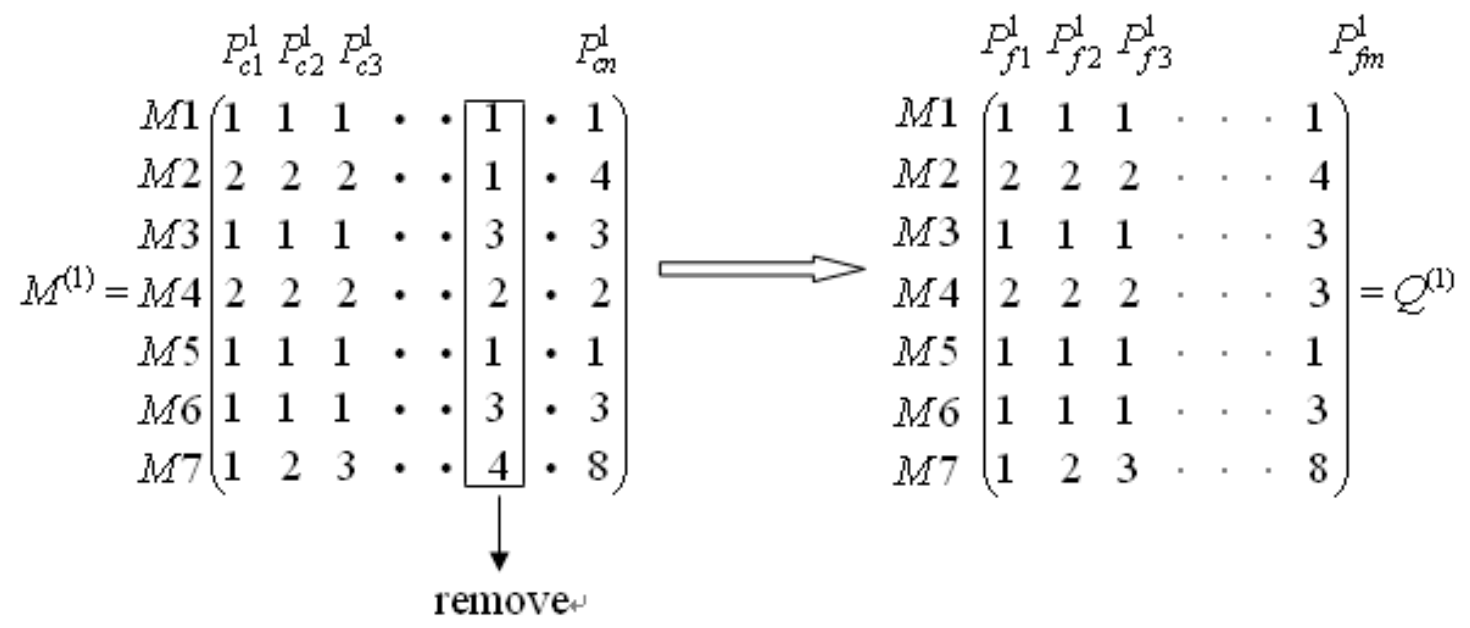

Fig. 5. An process of generation $Q^{(1)}$

\section{Step 3: generation of a low-carbon product family planning based on GA}

In this step, low-carbon product family planning will be generated based on a GA. GA is a search heuristic that mimics the process of natural evolution (i.e., selection, crossover and mutation). This heuristic is routinely used to generate useful solutions to optimize and search problems. In a genetic algorithm, a population is made up of strings. Each string represents a candidate solution to an optimization problem, which consists of a series of chromosomes. The algorithm seeks to evolve towards better solutions through a series of iterations. Two key issues of the GA need to be discussed to support low-carbon product family planning.

\section{The coding of chromosome}

The coding of the chromosome is the first step for the implementation of the genetic algorithm. In this paper, a coding approach of chromosome is presented for 
supporting low-carbon product family planning. An example of the chromosome is shown in Fig. 6, and it is described by natural number string. The chromosome has six genes, it denotes that a product family with six product variants. $Q^{(\mathrm{i})}$ of each product variant $i$ is stored in each gene respectively. For example, $Q^{(1)}$ has been stored in the first gene. Similar, $Q^{(2)}$ has been stored in the second gene. A feasible design scheme of each product variant combination forms the product family planning scheme which is represented by matrix, $D$. Which feasible design scheme of product variants is selected to form the product family planning depends on the natural number of the gene. For instance, as shown in Fig. 6, the number ' 3 ' appears in the first gene, it denotes that the third column of $Q^{(1)}$ is chosen to form the product family planning. The natural number in each gene is changeable based on genetic operations (i.e., selection, crossover and mutation). Therefore, the 'best' low-carbon product family planning scheme will be obtained by genetic operations. At the same time, the platform set which is represented by $M P$ will be obtained also. The different number of each row of matrix $D$ will form each row of $M$. For example, as shown in Fig. 6, two different numbers ' 2 ' and ' 4 ' appear in the second row of $D$, they form the second row of $M P$, and it means that M2(2) and M2(4) are two instance platforms of module M2 for product family design, and they will eventually be developed and manufactured. 


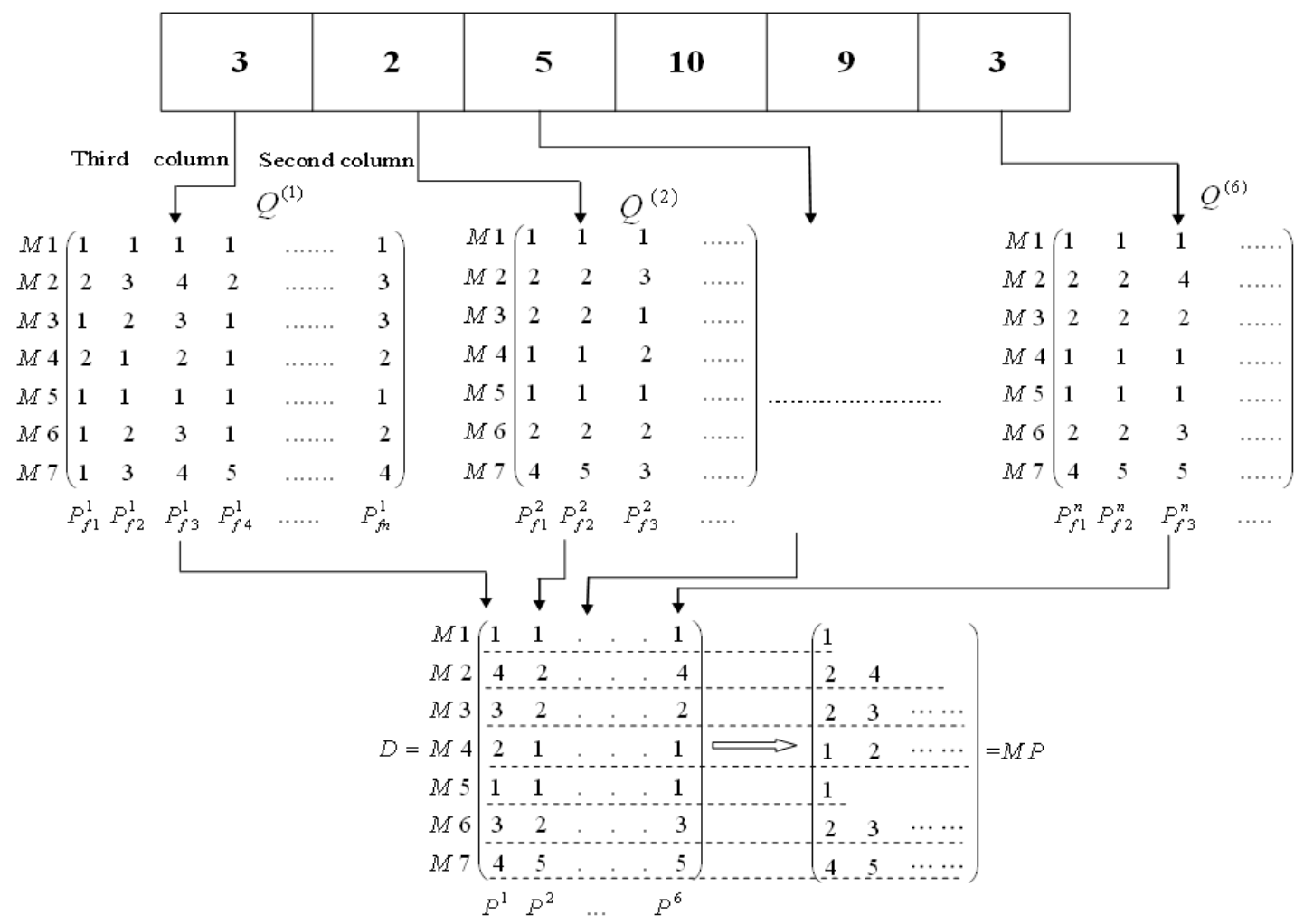

Fig. 6. An example of chromosome

\section{Fitness function}

The fitness function is regarded as a tool for evaluating the quality of the solution. Once the genetic representation and the fitness function are defined, a GA proceeds to initialize a population of solutions and then improves these solutions through repetitive application of mutation, crossover, inversion, and selection operators. There are many approaches which are developed to construct the fitness function for multiple-objective optimization problems. The weighted additive utility function is one of the most famous methods [27-28], and it is used in this paper. Let $f_{i k}$ be the $i$ th objective function of alternative $k$. The weighted additive utility function for alternative $k$ with two objectives can be represented as follows:

$$
U(k)=w_{1} f_{1 k}+w_{2} f_{2 k}
$$

where, $w 1$ and $w 2$ are the importance weights of each objective function. Each objective can be given a weight ranging from $0-1$ such that the total weight of two objectives has to be equal to 1 . Each weight can be set based on decision-maker's preference. Perhaps the performance indicators of different objective are on different 
scales. Hence, the weighted additive utility function with normalized objectives is represented as follows:

$$
U(k)=w_{1} f_{1 k}{ }^{\prime}+w_{2} f_{2 k}{ }^{\prime}
$$

where $f_{1 k}^{\prime}$ and $f_{2 k}{ }^{\prime}$ are normalized values of $f_{1 k}$ and $f_{2 k}$, respectively. Note that each normalized objective $f_{i k}$ 'is defined as:

$$
f_{i k}{ }^{\prime}=\frac{f_{i k}-f_{i k, \min }}{f_{i k, \max }-f_{i k, \min }}
$$

where $f_{i k \text {,min }}$ and $f_{i k \text {,max }}$ represent the given minimum and maximum values for objective function $f_{i k}$, respectively. In this paper, two objectives are GHG emission and cost of a product family.

\section{Case study}

For comparison, as shown in Fig. 7, the television receiver circuits in [13] was used to ascertain the validity optimization method presented in this paper. The television receiver circuit consists of seven modules. These modules are turner circuit M1, picture signal processing circuit M2, deflection circuit M3, color circuit M4, RGB driver M5, sound circuit M6 and power supply circuit M7. The candidate instances of each module and initial instance configuration of each product variant are shown in Fig. 2.

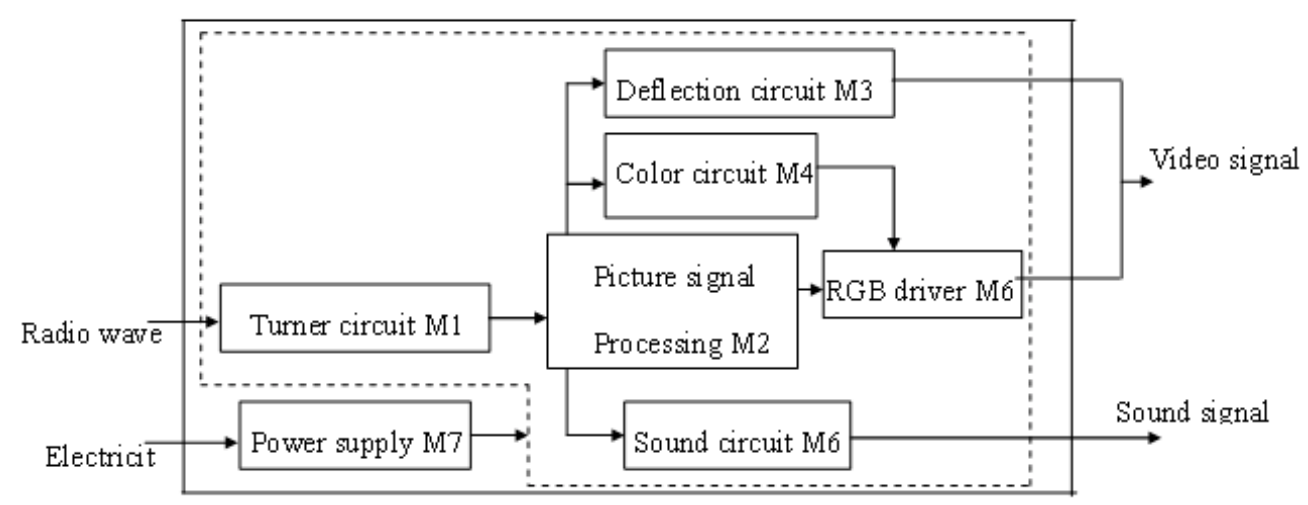

Fig.7. Modules of television receiver circuits

The coefficients of the cost are given as follows: $C_{f}^{0}=10,000,000, \alpha_{f}^{p}=3,000, \alpha_{f}^{M j}=9,000, \alpha_{v}^{m j}=0.65, \alpha_{v}^{f j}=1.5, \beta_{v}^{m j}=5$ for all $j$. 
$\gamma_{v}^{f}=0.95, c_{v}^{a}=10, r_{v}^{a}=0.95$. The production unit number of respective product variants is shown in Tab. 1.

Table 1 Production unit number of each product variant

\begin{tabular}{lcccccc}
\hline Product variant & $P^{(1)}$ & $P^{(2)}$ & $P^{(3)}$ & $P^{(4)}$ & $P^{(5)}$ & $P^{(6)}$ \\
\hline Product volume & 36,000 & 24,000 & 12,000 & 36,000 & 24,000 & 12,000 \\
\hline
\end{tabular}

The coefficients of the GHG model are assumed, based on practical information: $m_{\mathrm{N}}=0.005 \mathrm{~kg}, \quad E_{j}^{M}=5 \mathrm{kgCO}_{2} \mathrm{e} / \mathrm{kg}, \quad t_{v}^{f j}=0.005 \mathrm{~h} \quad$ for all $j ; \quad U=1, \quad E_{\mathrm{av} / 1}=100 \mathrm{kWh} / \mathrm{h}$,

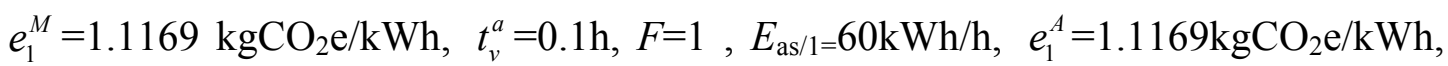
$E^{\mathrm{D}}=0.66 \mathrm{kgCO}_{2} \mathrm{e} / \mathrm{kg}, \quad S=1000 \mathrm{~km} \quad, \quad T_{\mathrm{w}}=22500 \mathrm{~h}, \quad E F=1.1169 \mathrm{kgCO}_{2} \mathrm{e} / \mathrm{kWh}$, $E_{j}^{E n d}=4 \mathrm{kgCO}_{2} \mathrm{e} / \mathrm{kg}$. These coefficients are selected for demonstration purpose rather than for precise assessment.

When the instances of each module of each product variant is selected based on initial module instance configuration, the cost and GHG emissions of the product family are shown in Fig. 8 and Tab 2 respectively. Perhaps the amount of GHG emissions of the product family is the lowest in such scenarios due to no consideration of any over-design.

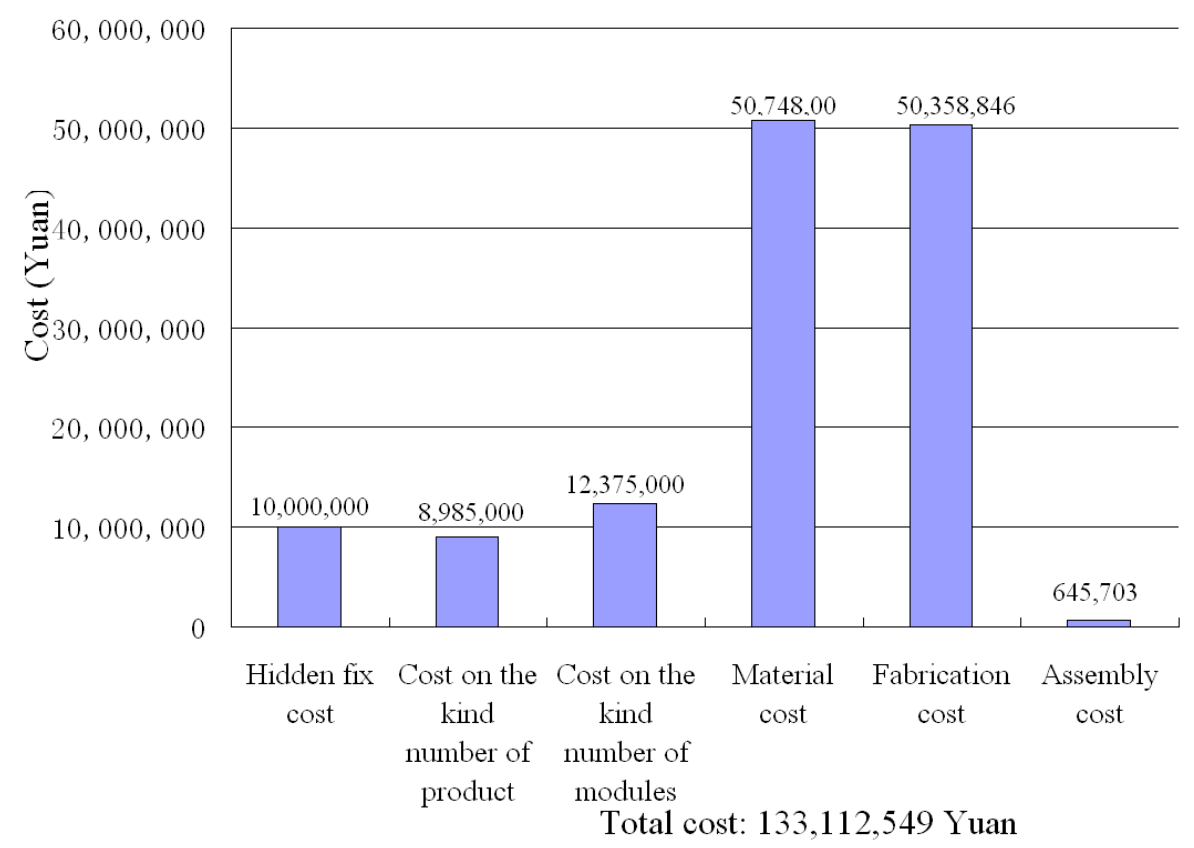

Fig .8. The cost of the product family under the initial instance configuration 
Table 2 GHG emission of the product family under the initial instance configuration

\begin{tabular}{clllccc}
\hline Stage & $\begin{array}{c}\text { Raw } \\
\text { material }\end{array}$ & $\begin{array}{l}\text { Manufacturin } \\
\mathrm{g}\end{array}$ & Distribution & Use & $\begin{array}{c}\text { End of } \\
\text { life }\end{array}$ & Total \\
\hline $\mathrm{GHG}\left(\mathrm{kgCO}_{2} \mathrm{e}\right)$ & $1,758,000$ & $22,353,900$ & 232,056 & $371,525,616$ & $1,406,400$ & $397,263,972$ \\
\hline
\end{tabular}

In low-carbon product family design, a designer has his/her preference range for the lowest cost and GHG emissions. However, since cost and GHG emission may be conflict with each other, the decision-maker should determine the importance weight of each objective function based on his/her preference. When a higher weight is assigned to the objective function of cost, the solution could bring about a lower cost. However, GHG emission could be greater. In contrast, when a higher weight is assigned to the objective function of GHG emission, the solution could lead to a lower GHG emission with a higher cost. In this paper, four different cases are analyzed as follows:

Case 1: When the minimum cost is considered by decision-maker, the importance weights are given as $w_{1}=1$ and $w_{2}=0$. The optimal procedure of GA is shown in Fig. 9.

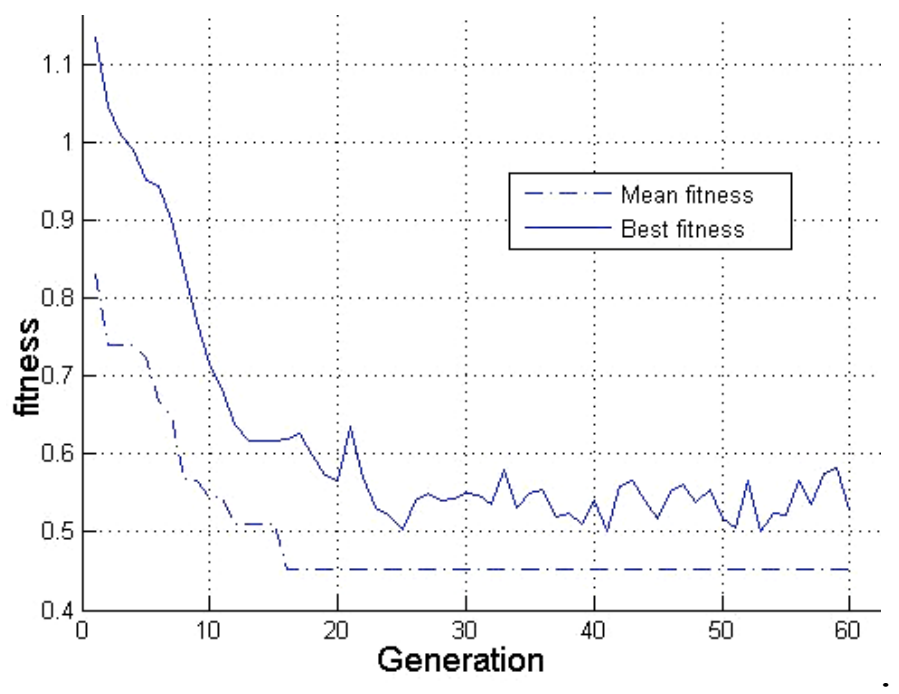

Fig. 9. GA optimal procedure

The product family planning scheme $D(1)$ and platform set $M P(1)$ are obtained as follows:

$$
\begin{aligned}
& P^{(1)} P^{(2)} P^{(3)} P^{(4)} P^{(5)} P^{(6)}
\end{aligned}
$$

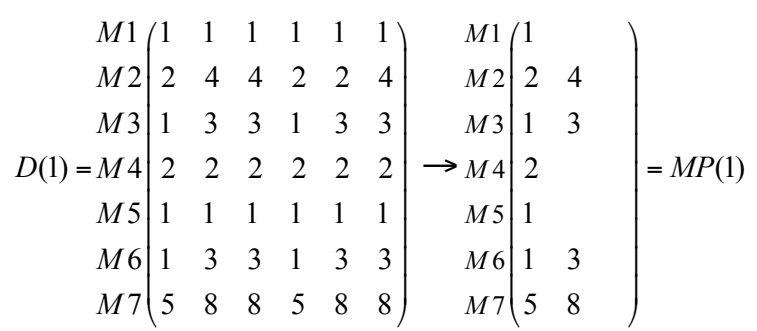


The result of optimization is the same as [14]. According to $M P(1)$, it can be observed that the total kind number of different module instance in product family planning scheme $D(1)$ is decreased. For example, according to initial module instance configuration of the product family, module instances M2(1), M2(3), M3(2), M4(1) and M6(2) are required, while they cannot be found in $M P(1)$, it means that these module instances will not need to be designed and manufactured if product family is planned on the basis of scheme $D(1)$, and they are replaced by other module instances. For instance, M2(2) and M2(4) are two instance platforms of M2, they have constituted other instances of M2 for the product family design. According to product family planning scheme $D(1)$, the total cost and GHG emission of the product family are calculated as shown in Fig. 10 and Tab. 3, respectively. Comparing with the initial module instance configuration of the product family, it can be observed that the total cost in case 1 is reduced by the platform strategy, while the GHG emission is increased due to over-design of some product variants.

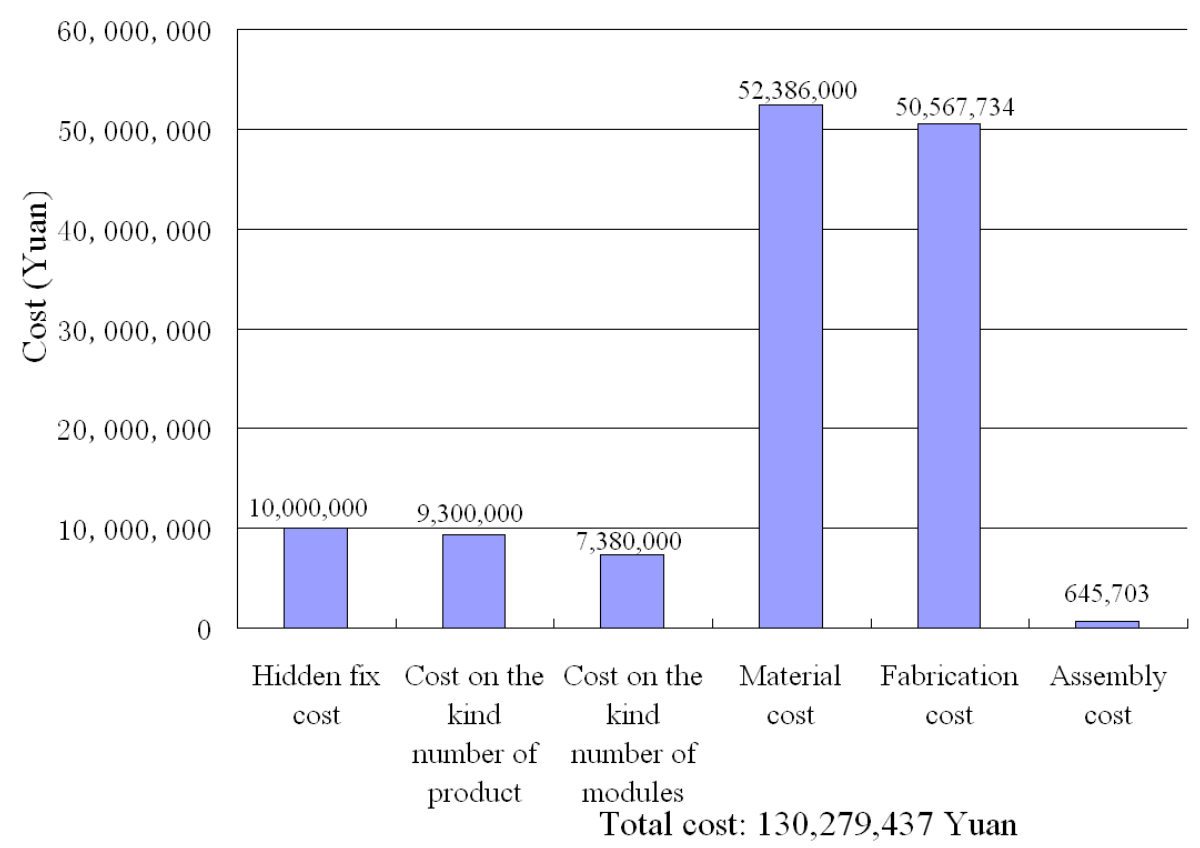

Fig.10.The cost of the product family planning scheme $D(1)$

Table 3.GHG emission result for the product family planning scheme $D(1)$

\begin{tabular}{clllccc}
\hline Stage & $\begin{array}{c}\text { Raw } \\
\text { material }\end{array}$ & $\begin{array}{l}\text { Manufacturin } \\
\mathrm{g}\end{array}$ & Distribution & Use & $\begin{array}{c}\text { End of } \\
\text { life }\end{array}$ & Total \\
\hline $\mathrm{GHG}\left(\mathrm{kgCO}_{2} \mathrm{e}\right)$ & $1,821,000$ & $22,431,900$ & 240,372 & $507,832,092$ & $1,456,800$ & $533,782,164$ \\
\hline
\end{tabular}


Case 2: When the decision-maker focus on cost, but the GHG emission is considered proper for social responsibility, the importance weights can be set as $w_{1}=0.6$ and $w_{2}=0.4$. The optimal procedure of GA is shown in Fig. 11.

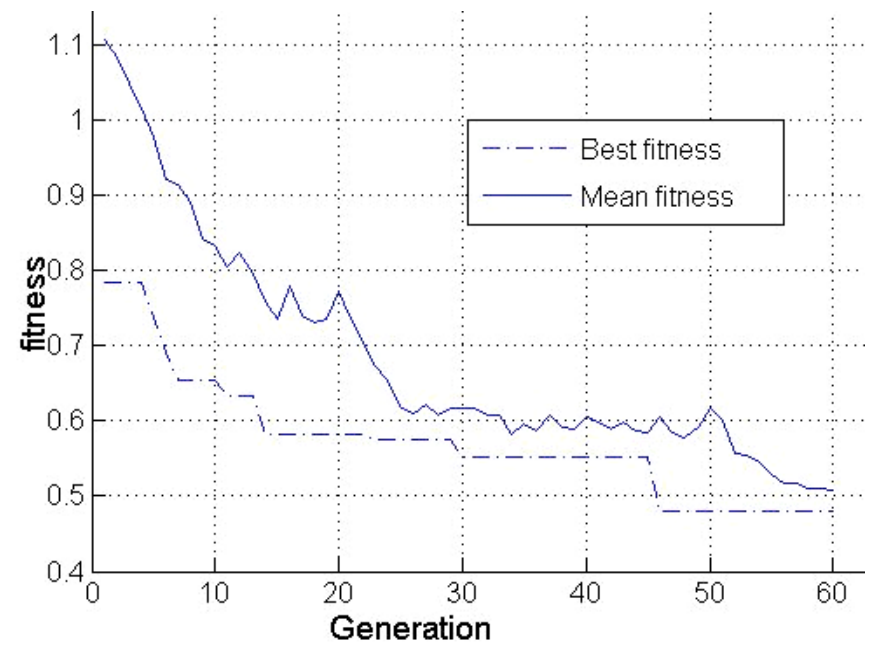

Fig. 11. GA optimal procedure

The product family planning scheme $D(2)$ and platform set $M P(2)$ are obtained as follows:

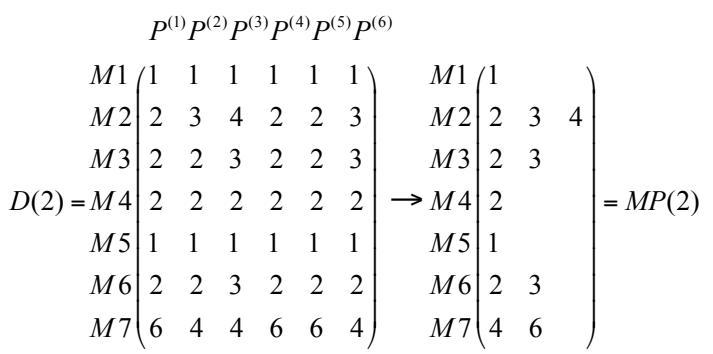

It can be observed that platform planning scheme and module instance configuration of some product variants are different with case 1. For example, M6(3) is shared by $P^{(2)}, P^{(5)}$ and $P^{(6)}$ in $D(1)$, while it cannot be shared by any product variants in $D(2)$. There are two possible reasons for this change. One possible reason is instance M6(3) with high GHG emission, such as it requires much raw materials to manufacture or it needs a lot of energy in using stage, etc. The other possible case is that M6(3) affects other module instance selection of a product variant because of the mutual constraint between module instances. The instance sharing scheme of other modules in product family planning scheme $D(2)$ is also changed apart from M6. According to product family planning scheme $D(2)$, the cost and GHG emissions of the product family are shown in Fig. 12 and Tab. 4 respectively. Comparing case 2 
with case 1 , we find that the cost in case 2 is greater than that in case 1 , while the GHG emission in case 2 is lower than that in case 1 .

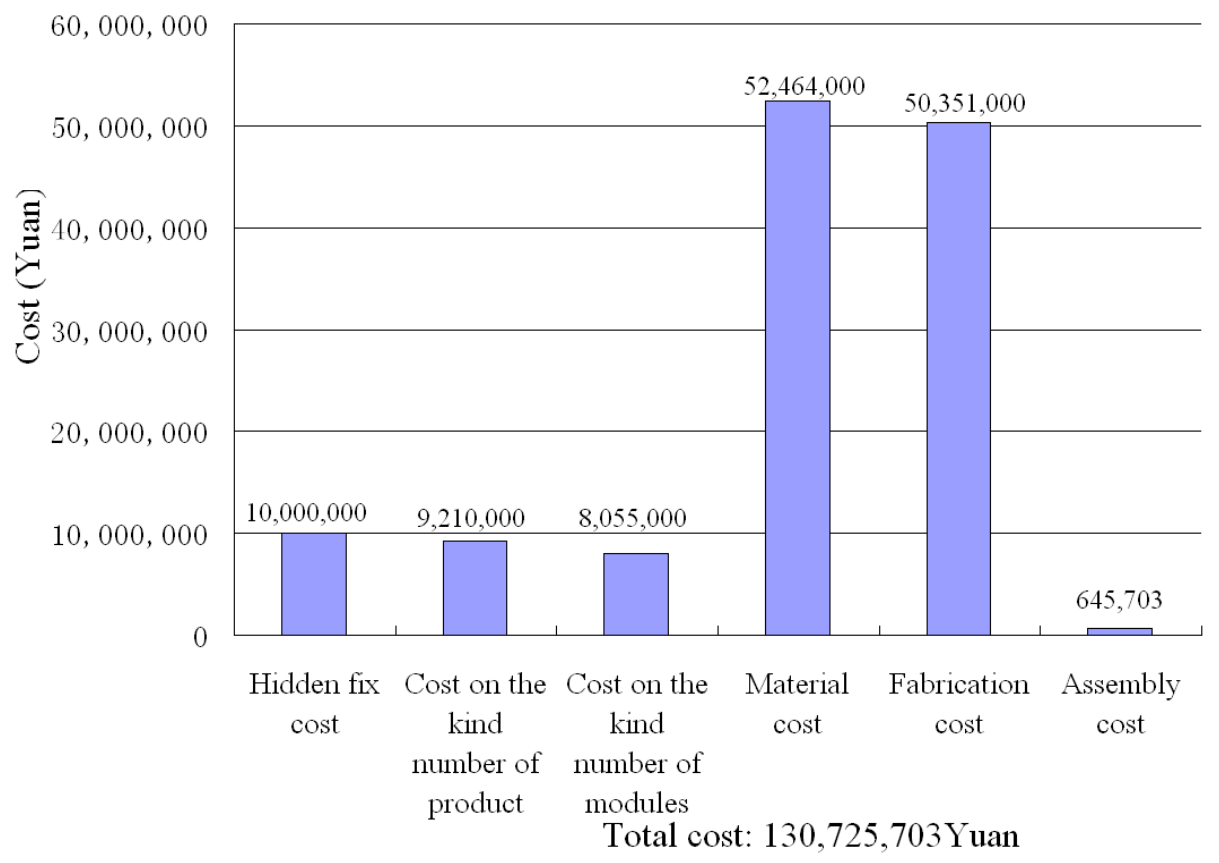

Fig. 12. The cost of the product family planning scheme $D(2)$

Table. 4 GHG emission result for the product family planning scheme $D(2)$

\begin{tabular}{clllccc}
\hline Stage & $\begin{array}{c}\text { Raw } \\
\text { material }\end{array}$ & $\begin{array}{l}\text { Manufacturin } \\
\mathrm{g}\end{array}$ & Distribution & Use & $\begin{array}{c}\text { End of } \\
\text { life }\end{array}$ & Total \\
\hline $\mathrm{GHG}\left(\mathrm{kgCO}_{2} \mathrm{e}\right)$ & $1,824,000$ & $22,351,900$ & 240,768 & $482,802,363$ & $1,459,200$ & $508,678,231$ \\
\hline
\end{tabular}

Case 3: When decision-maker think that protection the environment against pollution is as import as saving cost, the importance weights can be set as $w_{1}=0.5$ and $w_{2}=0.5$. The optimal procedure of GA is shown in Fig. 13.

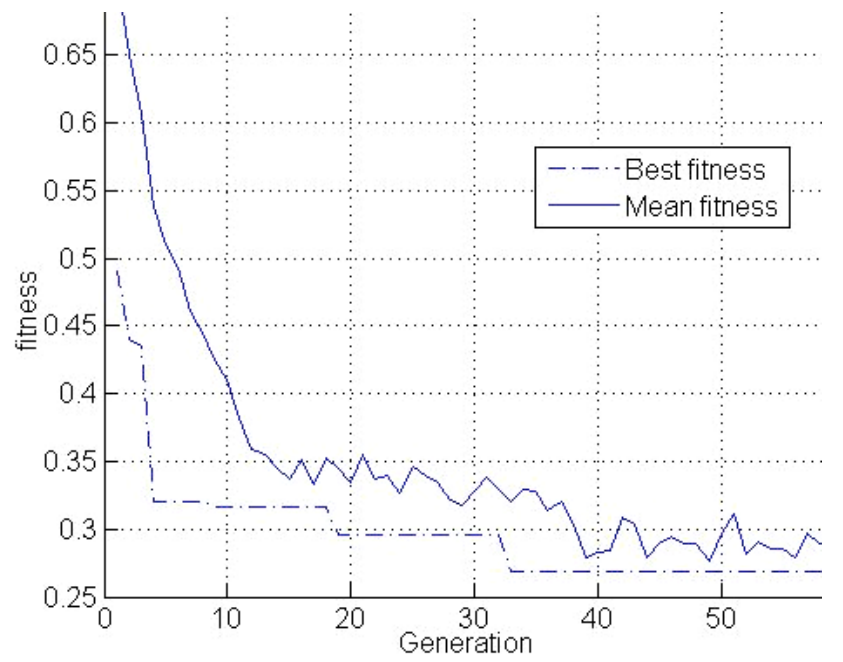

Fig. 13. GA optimal procedure.

The product family planning scheme $D(3)$ and platform set $M P(3)$ are obtained as 
follows:

$$
\begin{aligned}
& P^{(1)} P^{(2)} P^{(3)} P^{(4)} P^{(5)} P^{(6)}
\end{aligned}
$$

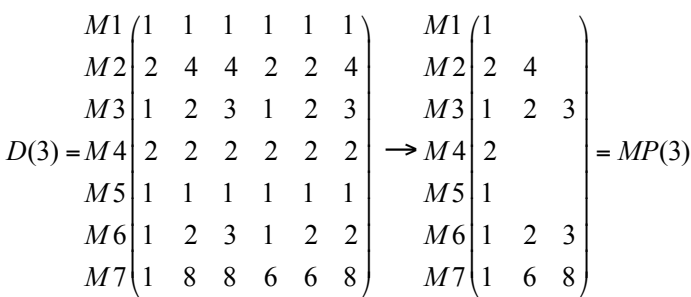

It can be observed that the total kind number of module instance in $M P(3)$ is greater than that in $M P(1)$ as well as in $M P(2)$. It means that more module instances type will be designed and manufactured if the product family is planned in accordance with $D(3)$. In addition, the platform planning scheme and sharing module instance scheme have also changed. According to planning scheme $D(3)$, the cost and GHG emissions of the product family are shown in Fig. 14 and Tab 5 respectively. Comparing case 3 with case 2 , the cost in case 3 is greater than that in case 2 due to more attention has been paid to the GHG emission in case 3. Although GHG emission is further decreased in case 3 , it is greater than that in case 1 . It is because some product variants still take the way of over-design in case 3.

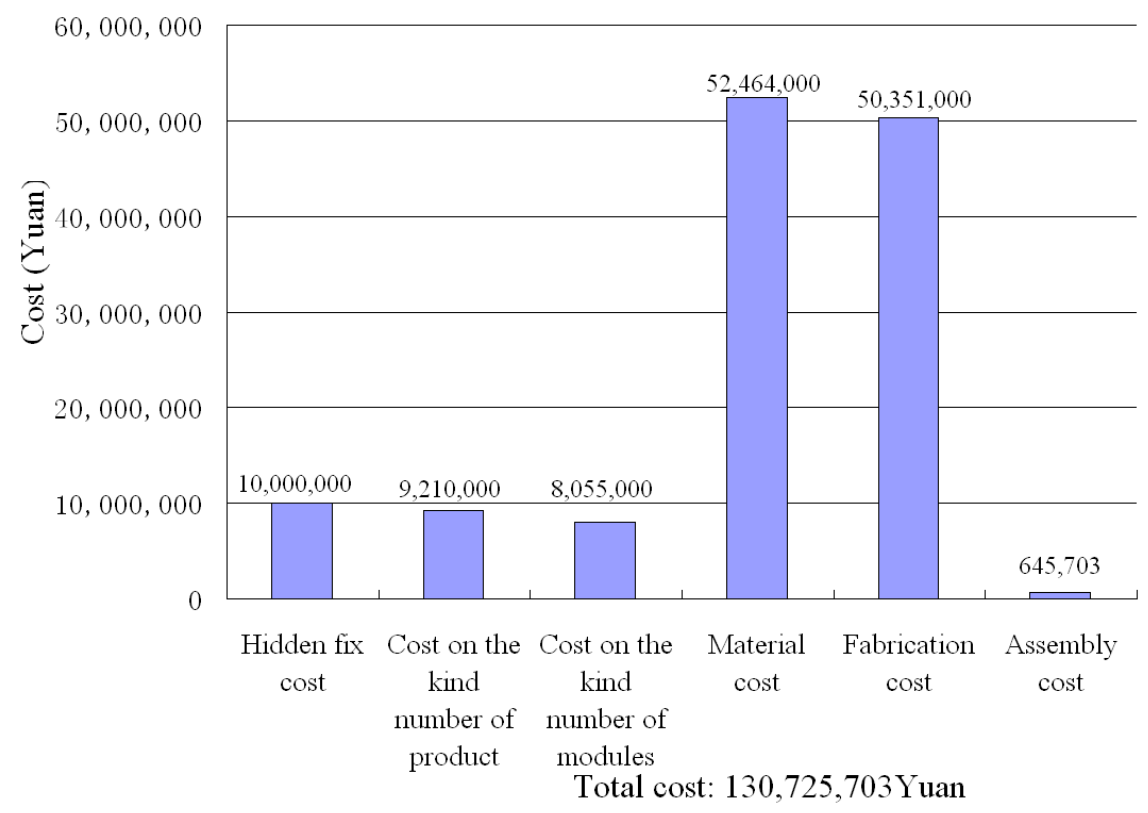

Fig. 14. The cost of the product family planning scheme $D(3)$

Table. 5 GHG emission result for the product family planning scheme $D(3)$

\begin{tabular}{cllllll}
\hline Stage & $\begin{array}{c}\text { Raw } \\
\text { material }\end{array}$ & Manufacturin & Distribution & Use & $\begin{array}{c}\text { End of } \\
\text { life }\end{array}$ & Total \\
\hline $\mathrm{GHG}\left(\mathrm{kgCO}_{2} \mathrm{e}\right)$ & $1,789,000$ & $22,341,900$ & 236,214 & $375,144,372$ & $1,431,600$ & $400,943,586$ \\
\hline
\end{tabular}


Case 4: The important weights $w_{1}$ and $w_{2}$ are studied ranging from $\left(w_{1}, w_{2}\right)=(0,1)$ to $\left(w_{1}, w_{2}\right)=(1,0)$ with an increment of 0.2 and $w_{1}+w_{2}=1$. The optimization result is shown in Fig.15. The result demonstrates that different important weights generate different results in accordance with bi-objective function values. In other words, as $w_{1}$ increases with an increment of 0.2 , the cost decreases and the GHG emission increases; as $w_{2}$ increases with an increment of 0.2 , the GHG emission decreases and the cost increases. Therefore, it represents a significant trade-off between cost and GHG emission, and the decision-maker can choose product family planning scheme based on these Pareto optimal solutions.

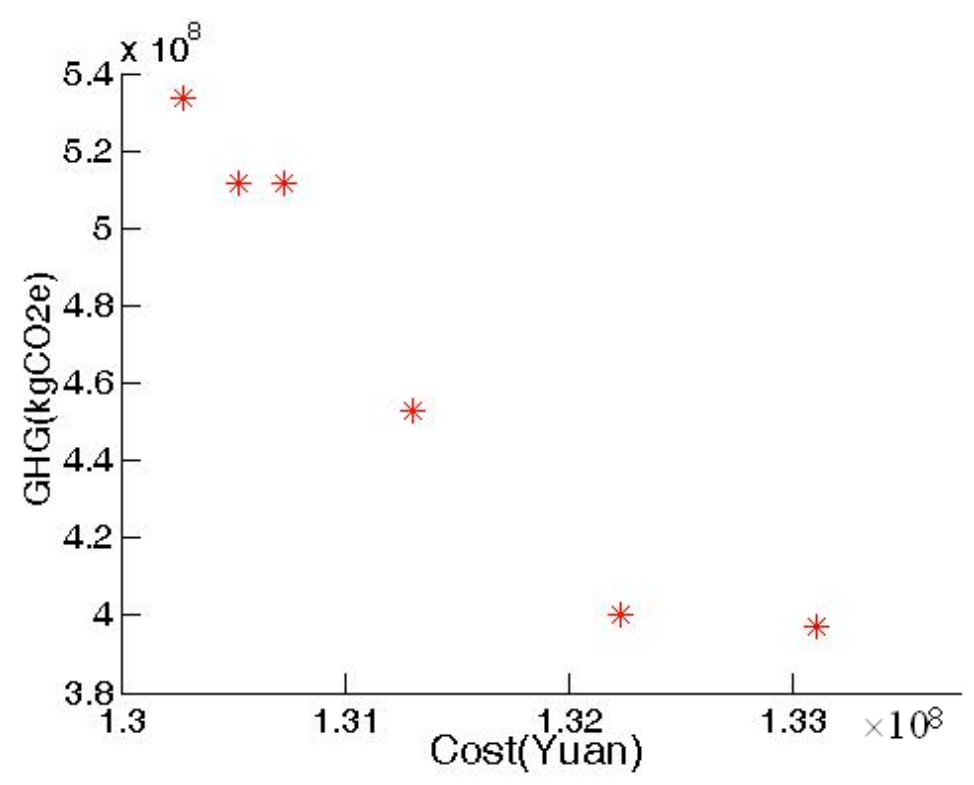

Fig.15. Plots of cost versus GHG with two important weights ranging from 0 to 1

\section{Conclusions}

As the issues concerning GHG emission have gradually attracted the attention of enterprises, product design with consideration of low-carbon has become more and more common. The platform planning method not only influences cost of a product family, but also determines the GHG emission of all product variants in the family. The cost has been mainly focused for platform planning in previous study, and environment concerns have been ignored. This paper has proposed a low-carbon product family design. In low-carbon product family design, product platform planning not only pays close attention to production cost, but also considers 
environmental impact. In this paper, the GHG emission model of a product family is constructed to evaluate the environment impact of product family. A bi-objective low-carbon product family design model is developed to optimize both the cost and the GHG emission. Moreover, an optimization method is employed to solve bi-objective problem for low-carbon product family design. The optimization method has three steps: (1) through an enumeration algorithm the initial design scheme set $M(\mathrm{i})$ of each product variant $i$ is generated. (2) the feasible design scheme set $Q(i)$ of each product variant $i$ is obtained by filtering some unfeasible design scheme from $M(i)$ (3) generation of a low-carbon product family planning based on bi-objective GA. Finally, a case study is introduced for testing the effectiveness of the method. The result is shown that the different module instance sharing scheme and different product platforms are obtained by setting weight for each objective in bi-objective GA based on decision-maker's preference.

For a real application, the future work is needed to investigate the methodology on how to gather appropriate information from practice that can fit with our optimization framework, and then the cost and carbon emission modeling should be considered to improve and expand. In addition, a better optimization method should be considered to develop in low-carbon product family for saving computational cost.

\section{Acknowledgements}

This research was carried out as a part of the CASES project which is supported by a Marie Curie International Research Staff Exchange Scheme Fellowship within the 7th European Community Framework Programme under the grant agreement No 294931. This research was also supported by National Science Foundation of China (No. 51175262); and Jiangsu Province Science Foundation for Excellent Youths under Grant BK20121011. 


\section{References}

[1] Intergovernmental Panel on Climate Change (IPCC). IPCC Fourth Assessment Report: Climate Change 2007; Working Group III Report “Mitigation of Climate Change” ;2007, pp. $447-496$.

[2] Lee, K.H., 2011. Integrating carbon footprint into supply chain management: the case of Hyundai Motor Company (HMC) in the automobile industry. Journal of Cleaner Production 19(11), pp. 1216-1223.

[3] M. Charter and U. Tischner.,2011. Sustainable solutions: developing products and services for the future, Greenleaf Publishing, Sheffield, UK.

[4] Song, J.S., Lee, K.M., 2010. Development of a low-carbon product design system based on embedded GHG emissions. Resources, Conservation and Recycling 54(9), pp. 547-556.

[5] Kuo, T.C., 2013. The construction of a collaborative framework in support of low carbon product design. Robotics and Computer-Integrated Manufacturing 29(4), pp. 174-183.

[6] Finkbeiner M., 2009. Carbon footprinting-opportunities and threats. International Journal of Life Cycle Assessment 14(2), pp: 91-94.

[7] Qi, Y., Wu, X.-B., 2011. Low-carbon technologies integrated innovation strategy based on modular design. Energy Procedia 5, pp: 2509-2515.

[8] Bocken, N.M.P., Allwood, J.M., Willey, A.R., King, J.M.H., 2011. Development of an eco-ideation tool to identify stepwise greenhouse gas emissions reduction options for consumer goods. Journal of Cleaner Production 19(12), pp: 1279-1287.

[9] Zhang X.F, Zhang S.Y, Hua Z.Y, Cheng GY, Pei H, Sa RN.,2012. Identification of connection units with high GHG emissions for low-carbon product structure design. Journal of Cleaner Production 27, pp: 118-125.

[10] Su,J C P., Chu,CH.,2012 A decision support system to estimate the carbon emission and cost of product designs. International Journal of Precision Engineering and Manufacturing 13(7), pp: 1037-1045. 
[11] Kuo, T C., Chen, H. M., Liu, C. Y., Tu, J. C., \& Yeh, T. C.,2014 Applying multi-objective planning in low-carbon product design. International Journal of Precision Engineering and Manufacturing 15(2), pp: 241-249.

[12] Pirmoradi Z., Wang G G., 2011 Recent advancements in product family design and platform-based product development: A literature review, International Design Engineering Technical Conferences \& Computers and Information in Engineering Conference, Washington, DC, ASME, Paper NO. DETC2011-47959.

[13] Fujita, K., Sakaguchi, H. and Akagi, S., 1999, Product Variety Deployment and its Optimization under Modular Architecture and Module Commonalization, ASME Design Engineering Technical Conference, Las Vegas, NV, Paper No.DETC99/DFM-8923.

[14] Martin, M. V. and Ishii, K., 1996, Design for Variety: A Methodology for Understanding the Costs of Product Proliferation, ASME Design Engineering Technical Conferences and Computers in Engineering Conference, Irvine, CA, ASME, Paper No. 96DETC/DTM-1610.

[15] Martin, M. V. and Ishii, K., 1997, Design for Variety: Development of Complexity Indices and Design Charts, 1997ASME Design Engineering Technical Conferences, Sacramento, CA, ASME, Paper No. DETC97/DFM-4359.

[16] Martin, M. V. and Ishii, K., 2000, Design for Varity: A Methodology for Developing Product Platform Architectures, 2000 ASME Design Engineering Technology Conferences, Baltimore, MD, pp. DETC2000/DFM-14021.

[17] Park, J. and Simpson, T. W., 2008. Toward an activity-based costing system for product families and product platforms in the early stages of development, International Journal of Production Research 46, pp: 99 - 130.

[18] Johnson, M. D. and Kirchain, R. E., 2009. Quantifying the effects of product family decisions on material selection: A process-based costing approach, International Journal of Production Economics 120, pp: 653-668.

[19] Wang, W. D., Qin, X. S., Yan, X. T., Tong, S. R., and Sha, Q. Y.,2007. Developing a systematic method for constructing the function platform of product 
family, 2007 IEEE International Conference on Industrial Engineering and Engineering Management 1-4, pp: 60-64.

[20] Seepersad, C. C., Hernansez, G. and Allen, J.K.,2000, A Quantitative Approach to Determining Product Platform Extent. ASME Design Engineering Technical Conference, Baltimore, MD, Paper No. DETC2000/DAC-14288.

[21] Perera, H. S. C., Nagarur, N., \& Tabucanon, M. T., 1999. Component part standardization: A way to reduce the life-cycle cost of products. International Journal of Production Economics 60-61(1), pp: 109-116.

[22] Steva, E.D., et al., 2006. Two methodologies for identifying product platform elements within an existing set of products, International design engineering technical conference, Philadelphia, PA, ASME, Paper No. DETC2006-99234.

[23] Tucker, C.S. and Kim, H.M., 2008. Optimal product portfolio formulation by merging predictive data mining with multilevel optimization. Journal of Mechanical Design, 130 (4), 041103 (15pp).

[24] Khajavirad, A. and Michalek, J., 2008. A decomposed gradient-based approach for generalized platform selection and variant design in product family optimization. Journal of Mechanical Design, 130 (7), 071101 (8pp).

[25] Khajavirad, A., Michalek, J., and Simpson, T., 2009. An efficient decomposed multi-objective genetic algorithm for solving the joint product platform selection and product family design problem with generalized commonality. Structural and Multidisciplinary Optimization 39(2), pp: 187-201.

[26] Zhang X Y, Huang G Q, Rungtusanatham, MJ., 2008. Simultaneous configuration of platform products and manufacturing supply chains. International Journal of Production Research 46(21), pp: 6137-6162.

[27] Tangian A., 2004. A model for ordinally constructing additive objective functions. European Journal of Operational Research, 159, pp: 476- 512.

[28] Malakooti B., 2010. Independent, convergent, and divergent decision behaviour for interactive multiple objectives linear programming. Engineering Optimization 42(4), pp. 325-346. 